\title{
The Transient and Steady State Performance of A Shunt Active Filter Using Measured Site Data
}

\author{
Simon Round, Member, IEEE, Hamish Laird, Student Member, IEEE, Richard Duke, Member, IEEE, \\ Alister Gardiner.
}

\begin{abstract}
This paper presents the analysis of real power system events recorded at a light industrial site to determine the effect of a shunt active filter on power quality. The shunt active filter is shown to improve power quality by lowering the distortion of the supply voltage in both the transient and steady state. The shunt active filter power rating and other design information are also determined. The performance degradation of the shunt active filter when it has a limited rating is then demonstrated. In one case the voltage distortion is made worse by the active filter. The requirements that various transient events, including capacitor switching and induction motor starts, place on the shunt active filter design are outlined. These requirements are such that the required switching frequencies exceed those attainable with IGBTs and transient ratings dominate the active filter design constraints.
\end{abstract}

Keywords - Shunt active filter, Power quality measurements, Transient performance.

\section{INTRODUCTION}

Power quality has assumed an increased importance as customers demand better service from electrical supply companies and the companies look for ways to distinguish themselves from competitors in developing or newly deregulated electricity markets. In general the qualities that make electrical power have high quality are constant voltage level, low voltage harmonic distortion and a low number of disturbing transient events [1]. If these qualities cannot be achieved it is often necessary to install extra equipment to mitigate the effects of possible causes of low power quality. One such piece of equipment is the shunt active filter which operates to lower the harmonic current flowing in the $\mathrm{AC}$ system. The voltage distortion caused by the harmonic currents is an increasing problem around the world as the amount of electrical power processed by non-linear power electronic converters continues to increase $[1,2]$. The adverse effect of this voltage distortion on sensitive electronic loads is one of the results of low power quality. Therefore removing the harmonic current content in an AC system will, in general, improve the power quality.
Low power quality is very often caused by the sensitivity of equipment, not to steady state continuing situations, but to short term transient events such as sags, surges and system switchings. This means that an active filter installed to improve power quality should be evaluated and designed for its performance, not only in the steady state but also in transient conditions. Even if the active filter is designed for only steady state harmonic currents it will be subjected to transients in the course of normal operation.

In the past the performance of shunt active filters has been evaluated in steady state operation [3] and it is only recently that the transient performance has been considered and investigated. In these recent investigations the transients have been artificially created in the laboratory and have not been from actual measured transient incidents from a real site [4]. The emphasis has also been on the multiple cycle response of the filter rather than on the effect of the device on the voltage waveform and the power quality.

This paper deals with the evaluation of a shunt active filter to improve power quality and to determine suitable active filter ratings. The effects of a filter installed at a light industrial site are determined by simulation of the site system when driven by actual measured transient and steady state events collected at a winery over a twelve-month period. In order to show the performance of the shunt active filter the Total Harmonic Distortion (THD) of the voltages and currents are used as figures of merit along with the voltage and current waveforms themselves. The shunt active filter performance when converters of limited capability are used is also investigated. In order to evaluate the performance of a shunt active filter the recorded site data is used to drive a shunt active filter model. A number of transient events and steady state conditions are used to determine the effect of the filter on the power quality and at the same time the required active filter rating is determined. Design requirements such as typical operating current, overload current and suitable switching frequency are produced. These design rating decisions directly effect the capital cost of the unit and the operating costs.

Automated measurement of system voltages and currents have been taken for over a year at a winery site in New Zealand (shown in Figure 1). The site is supplied through a dedicated $11 \mathrm{kV}-415 \mathrm{~V}$ transformer. The $11 \mathrm{kV}$ is reticulated by underground cable and is supplied by a $50 \mathrm{kV}$ to $11 \mathrm{kV}$ substation which links into a $50 \mathrm{kV}$ sub transmission network. The site load is composed mainly of direct on-line connected induction motors most of which are used to drive centrifugal 
pumps. There are also two $260 \mathrm{~kW}$ induction motors (IM) that drive refrigeration compressors. Power factor correction capacitors (PFC) are also connected. The main harmonic producing loads at the site are two half-wave rectifier units used to maintain operating temperature in the compressor motors to prevent water ingress when they are not operating. The use of this type of heater is common in New Zealand dairy factories where induction motors operate in wet environments. A more complete description of the site and measurements is given in [5].

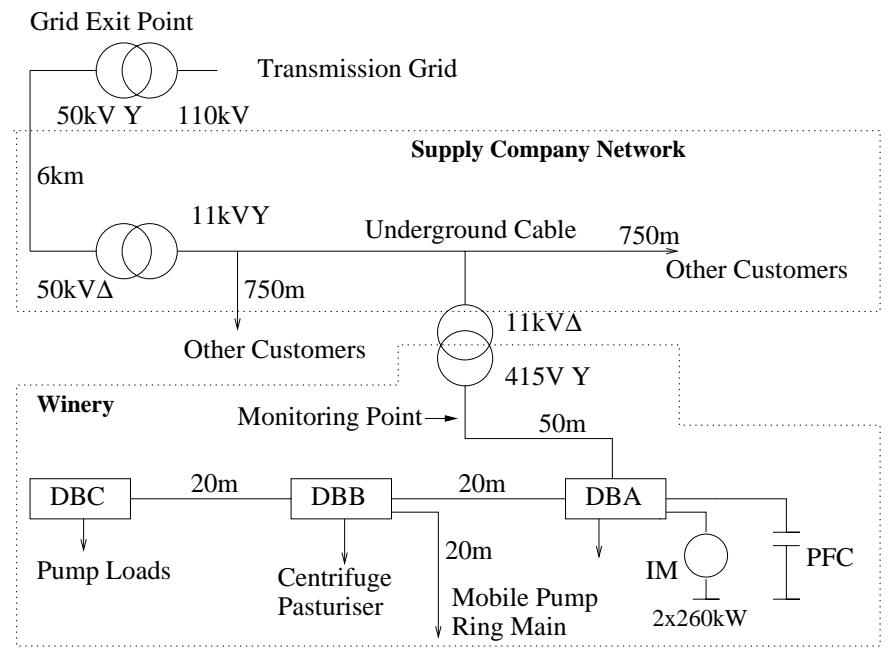

Figure 1 Winery Site and AC System

\section{Determining The Performance of Shunt Active FILTER AS A POWER QUALITY IMPROVEMENT SYSTEM}

The shunt active filter system considered in this paper is a load side active filter and is shown schematically in Figure 2.

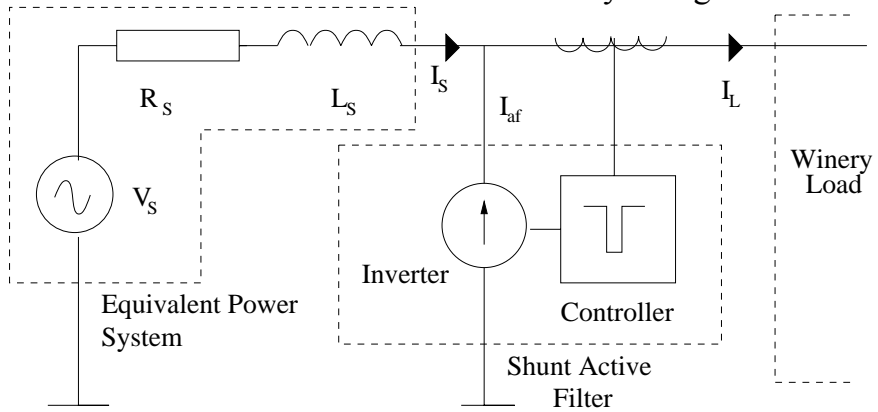

Figure 2. Load Side Shunt Active Filter System

The filter operates by determining the harmonic content of the load current, $\mathrm{I}_{\mathrm{L}}$, and injecting the antiphase compensating current, $\mathrm{I}_{\mathrm{af}}$, to cancel the harmonics. To determine the performance of a shunt active filter a model of the filter and AC supply system was developed in Matlab-Simulink. The AC system is modelled simply as a voltage source and a passive resistor-inductor system impedance. The compensating current is determined using a second order notch filter with $40 \mathrm{~dB}$ rejection at $50 \mathrm{~Hz}$ and a notch width of $5 \mathrm{~Hz}$ [6]. Other methods to determine the compensating current include the Instantaneous Reactive Power Theorem (IRPT) [7], the Synchronous Reference Frame [8], the Fast Fourier Transform (FFT) method and sinusoidal subtraction methods [4]. The active filter model assumes that the filter converter has an infinite current capability and has no current slew rate limit. As such it is capable of determining suitable active filter ratings from the measured steady state and transient events. The supply current is determined by subtracting the compensating current from the load current. In order to estimate the effect of the active filter on the site voltage the impedance of the $\mathrm{AC}$ system and the system voltage, $\mathrm{V}_{\mathrm{S}}$, are required. These are estimated using an FFT based frequency domain approach. This method gives reasonably consistent results for all the test events and is reasonably accurate when the terminal voltage from the model is compared with the measured terminal voltage. The estimates for the site are a system inductance, $\mathrm{L}_{\mathrm{s}}$, of $43 \mu \mathrm{H}$ and a system resistance, $R_{s}$, of $0.029 \mathrm{~m} \Omega$. These values have been found to agree with estimates from representative PSCAD models of the AC system.

\section{Performance of The Shunt ACtiVe Filter}

A transient incident that is shown in Figure 3, starting at time $320 \mathrm{~ms}$, is caused by a small load change which excites a system resonance at approximately $450 \mathrm{~Hz}$. The operation of both compressor induction motors makes the load level $510 \mathrm{~kW}$ and capacitors are connected to ensure that the power factor is close to unity.

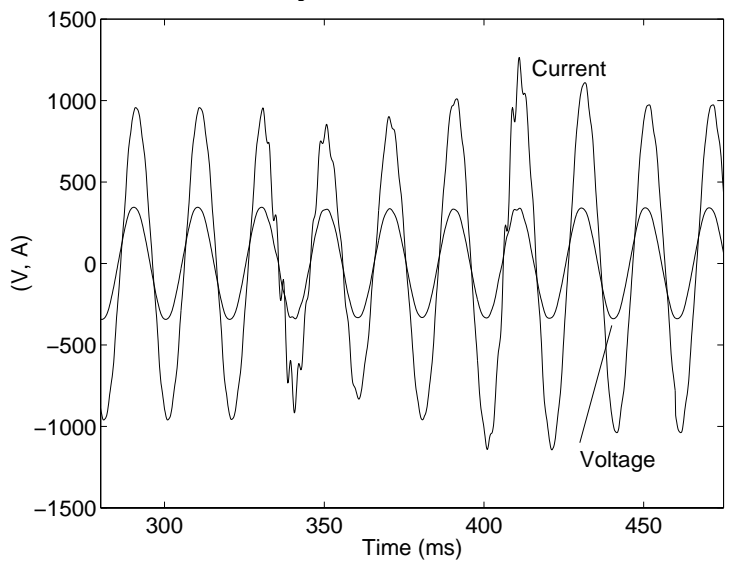

Figure 3. Load Current and Site Voltage During a Transient Load Change

Figure 4 shows the compensating current that the active filter must produce as a result of the transient incident along with the supply current which is sinusoidal and has only a slight dip during the transient. Figure 5 shows the effect of the active filter on the supply current distortion. The load current THD is approximately $3 \%$ before the transient increasing to a peak of almost $18 \%$ during the transient and falling to $5 \%$ after the transient. The difference in the load current THD before and after the transient is due to the load change. The supply current THD is less than $2 \%$ during the transient and is below $1 \%$ in steady state both before and after the transient event. 


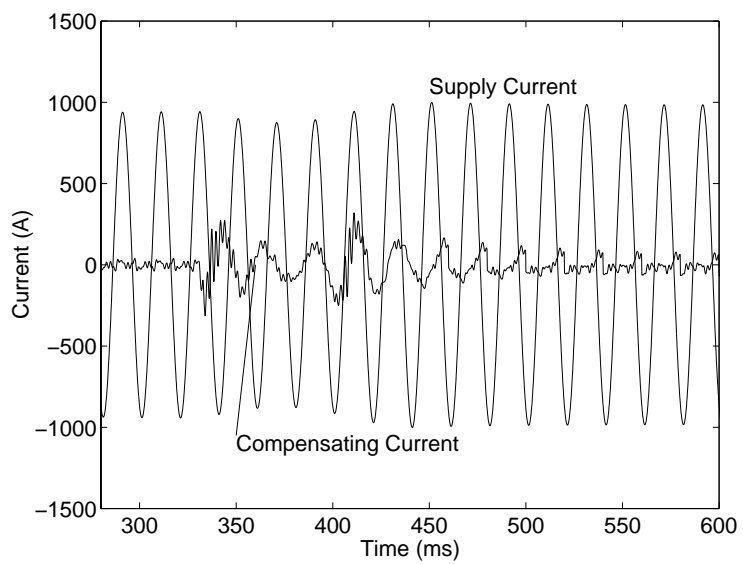

Figure 4 Supply Current and Active Filter Compensating Current

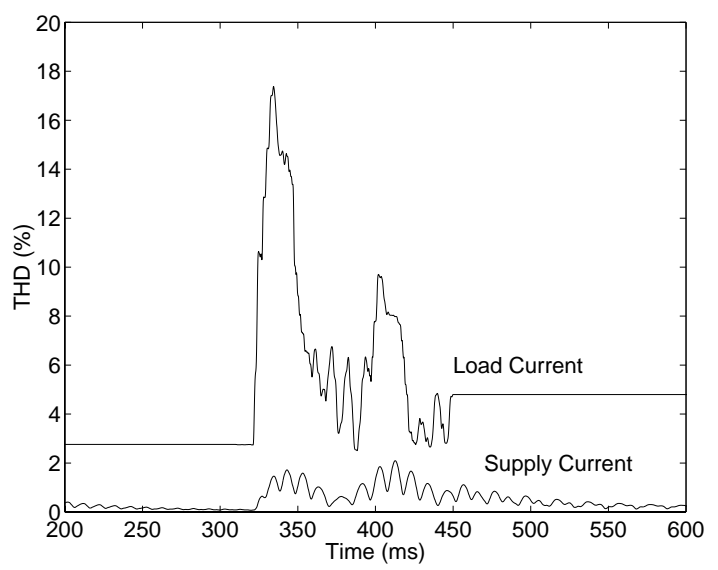

Figure 5 Load and Supply Current THD in Steady State and During a Transient

In order to compensate for the transient the active filter produces a compensating current that has a maximum of 319 Amps peak, while the steady state current is 24 Amps peak. The shunt active filter's required instantaneous kVA rating is shown in Figure 6. The peak rating of 40kVA is almost ten times larger than the steady state rating of approximately $4 \mathrm{kVA}$.

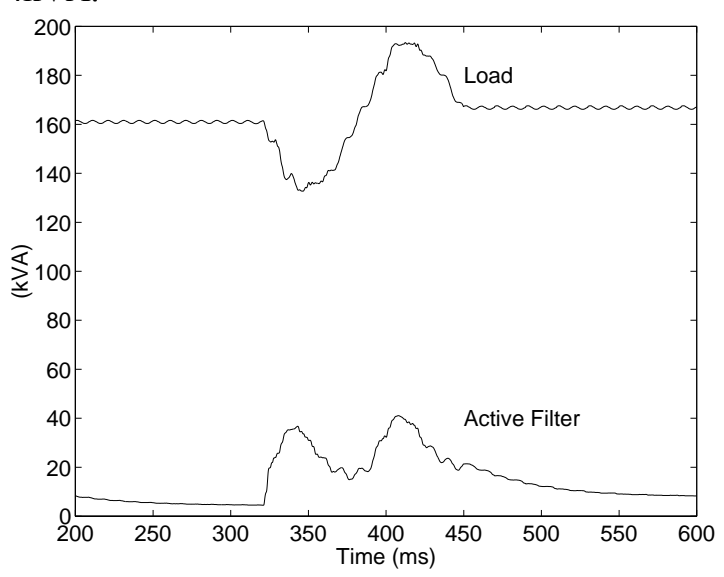

Figure 6 Instantaneous Load and Shunt Active Filter Rating

The filter's effect on the voltage waveform's THD is shown in the Figure 7. After active filtering the voltage THD during the transient is less than $0.5 \%$, lowered from a peak of $3.5 \%$ before active filtering. This shows that the active filter improves the quality of the supplied power by reducing the THD of the voltage during both the steady state and the transient. The transient rating requirement dominates the filter specification and the converter needs a short term $(150 \mathrm{~ms})$ rating of 170 Arms with a peak current rating of 319 Amps if it is to perform active filtering for this transient. Therefore, the devices selected for use in the active filter converter would need to be chosen largely for the transient condition and the large current rating would only be used during the transient.

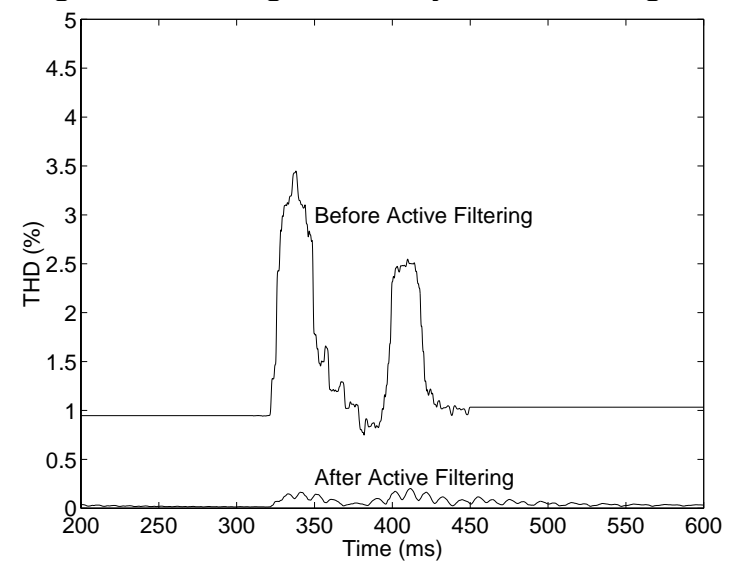

Figure 7 Voltage THD before and after Active Filtering

\section{EFFECT OF NON IDEAL SHUNT ACTIVE FILTER PERFORMANCE ON POWER QUALITY DURING TRANSIENTS}

The previous section has shown the steady state and transient ratings that are appropriate to reduce the voltage distortion. The required ratings were $40 \mathrm{kVA}$ in the transient and $4 \mathrm{kVA}$ in the steady state corresponding to compensating currents of 170 Arms and 17 Arms respectively. It is unlikely that an active filter converter would be built to that specification. Modern switching devices have impressive overload capability, but the transient specification requires excessively large and costly switching devices. A lower cost approach would be to use a converter with a lower maximum current and to control the converter within this limit. Active filter converters are usually sufficiently controllable to allow such a strategy. Figure 8 shows the supply current for the previously described transient incident when the active filter current limits if compensating current requirements exceed its rating. The decreasing current limit from no current limit, (No CL on Figure 8), to no active filtering (No AF) shows that the supply current distortion increases as the current limit decreases. The $50 \mathrm{~A}$ current limit corresponds to a $12 \mathrm{kVA}$ rating and $100 \mathrm{~A}$ to a $24 \mathrm{kVA}$ rating. The current limit in this case is a hard current limit that simulates the response of a converter current control protection system. In a real active filter, the controller will adjust the compensating current such that it is below the absolute current limit. The current will be continuous however this is still a current limiting action.

The supply current THD for the same conditions is shown in Figure 9. The transient supply current THD rises as the current limit is decreased. When the shunt active filter current limit is 50 Amps the supply current THD is almost the same as that of the original load current. 


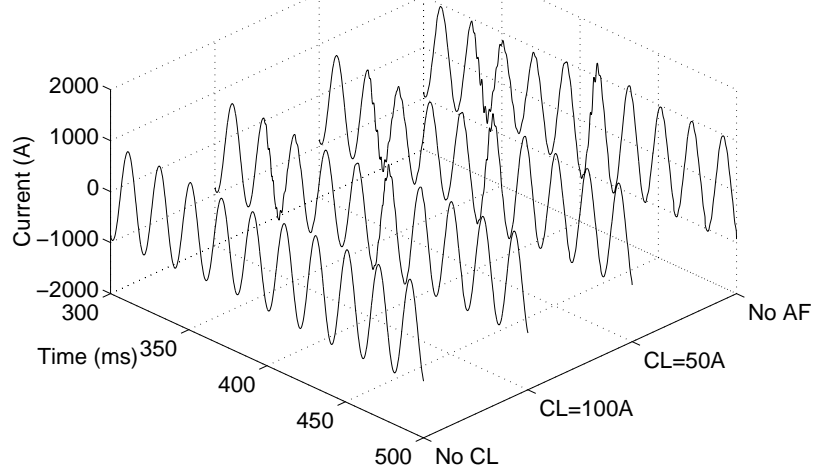

Figure 8 Supply Currents when the Active Filter has Limited Current Rating (from no current limit, No CL, to no active filter, No AF)

The voltage THD variation for the same cases is shown in Figure 10. As was seen with the current THD, decreasing the current limit increases the THD of the voltage waveform. With the current limit at 50A the supply voltage THD during the transient is actually greater than that without active filter operation. This indicates that it is possible for an active filter using this method of current limiting to further lower the power quality during a transient.

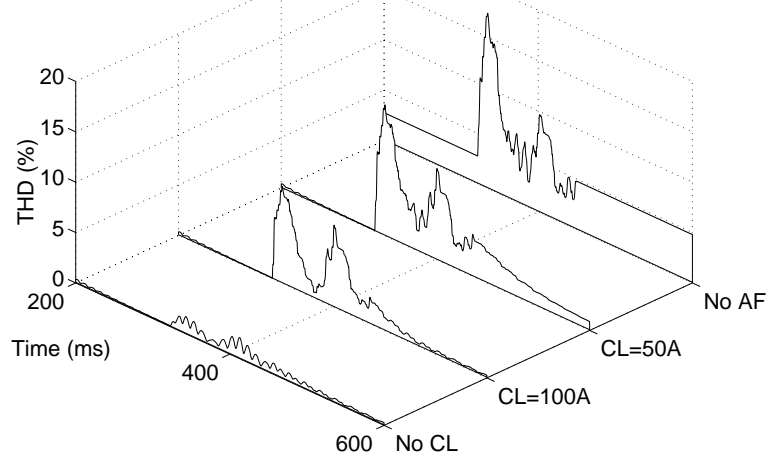

Figure 9 Effect of Limited Rating on Supply Current THD

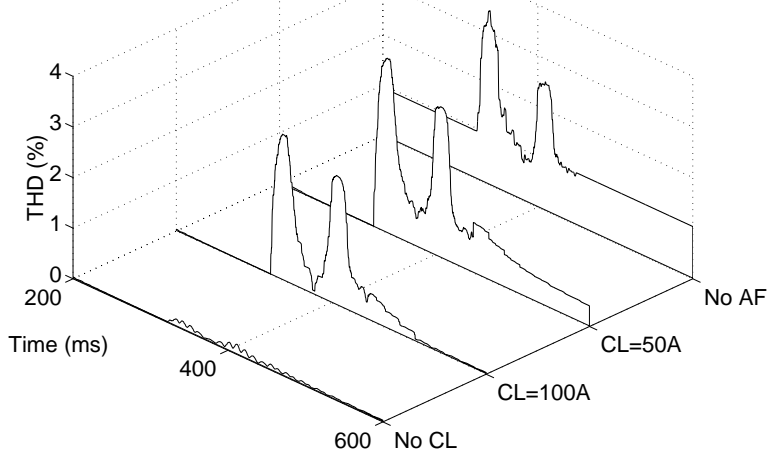

Figure 10 Effect of Limited Rating on Supply Voltage THD

\section{OTHER TRANSIENT EVENTS}

The shunt active filter will be installed to lower the harmonic current flowing in the AC system in the steady state. It is also capable of improving the power quality during transient events such as the example from the previous section. There are a number of other types of transient events that occur at the winery site such as load switching, capacitor bank switching and voltage sags and surges. Not all of these events are usually viewed as harmonic events but they all contain components at non-fundamental frequencies and as such they are detected by the active filter controller.

\section{A. Induction Motor Start}

The most common event that occurs at the winery site is the starting of induction motors. Figure 11(a) below shows the initial start current and voltage transient for one of the refrigeration compressors' $260 \mathrm{~kW}$ induction motors.
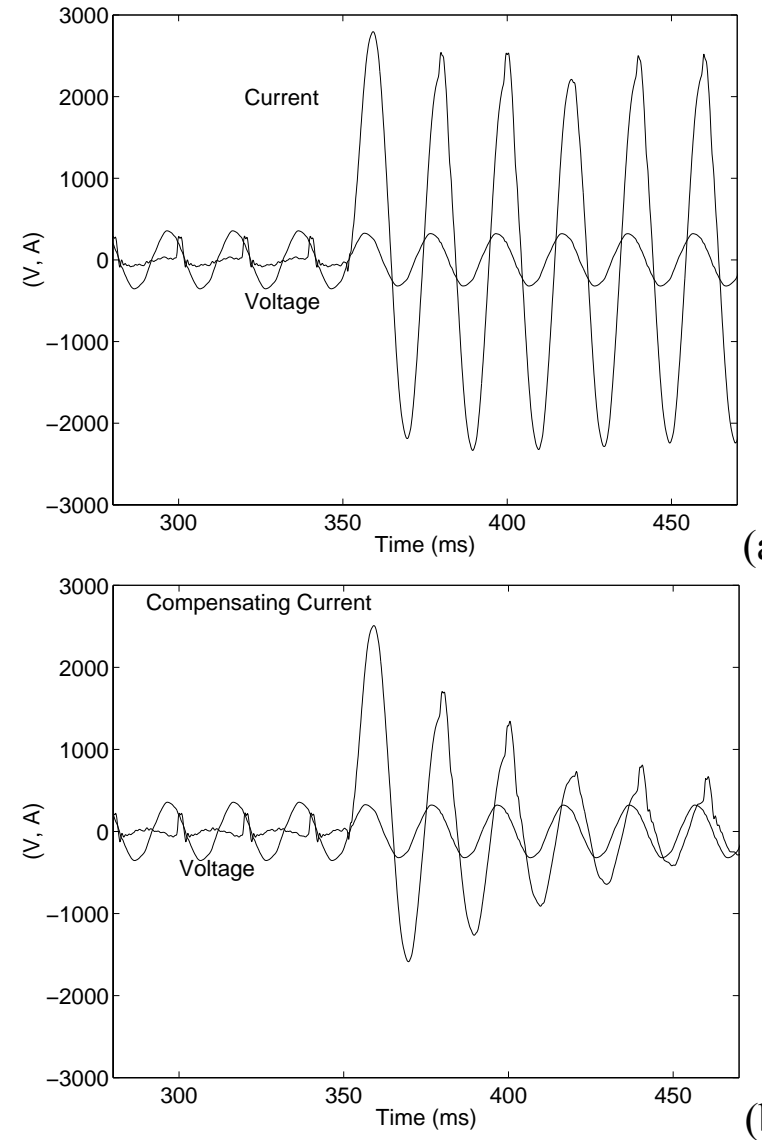

Figure 11 Induction Motor Start Transient (a) Supply Voltage and Motor Current (b) Supply Voltage and Compensating Current

When this transient is applied to the active filter model the compensating current generated, shown in Figure 11(b), is initially as large as the motor start current with a 2509 Amp peak. The maximum rate of change of current is 0.73 Amps/ $\mu \mathrm{s}$. The magnitude of the compensating current falls as the transient response of the notch filter decays. 


\section{B. Power Factor Correction Capacitor Switching}

Power factor correction capacitor banks connected at the site are switched to ensure that VA demand limits are not exceeded. When the power factor capacitors are switched a transient oscillation occurs as is shown in Figure 12 at time $330 \mathrm{~ms}$.

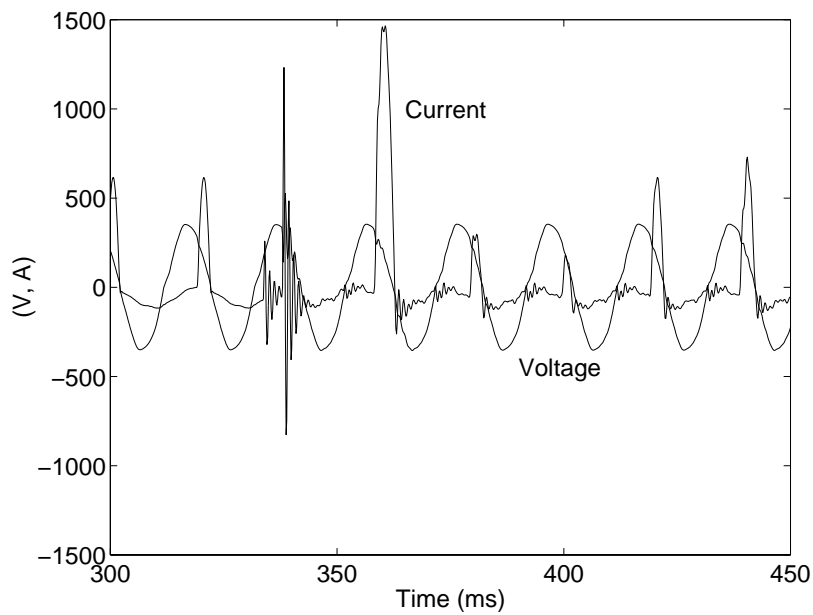

Figure 12 Capacitor Bank Switching Transient

A large oscillation occurs in both the current and voltage and the transient oscillation causes the induction motor heater unit to produce the $1300 \mathrm{~A}$ peak after the capacitor switching. The heater units are the cause of the spiked current [5]. In order to filter this transient the shunt active filter must produce a compensating current with a peak of 1300 Amps and the maximum rate of change of current is $6.3 \mathrm{Amps} / \mu \mathrm{s}$. In doing this the active filter lowers the supply current THD from $120 \%$ to less than $20 \%$.

\section{Voltage Sag}

One of the most common events that effects power quality is the voltage sag caused by AC system faults. The sag has little effect directly on the active filter as the filter's current control acts to reject any disturbance in the voltage. However the sag can have a large effect on the load current from which the compensating current is determined. Figure 13 shows the end of a sag event and shows the response of an induction motor heating unit to this sag.

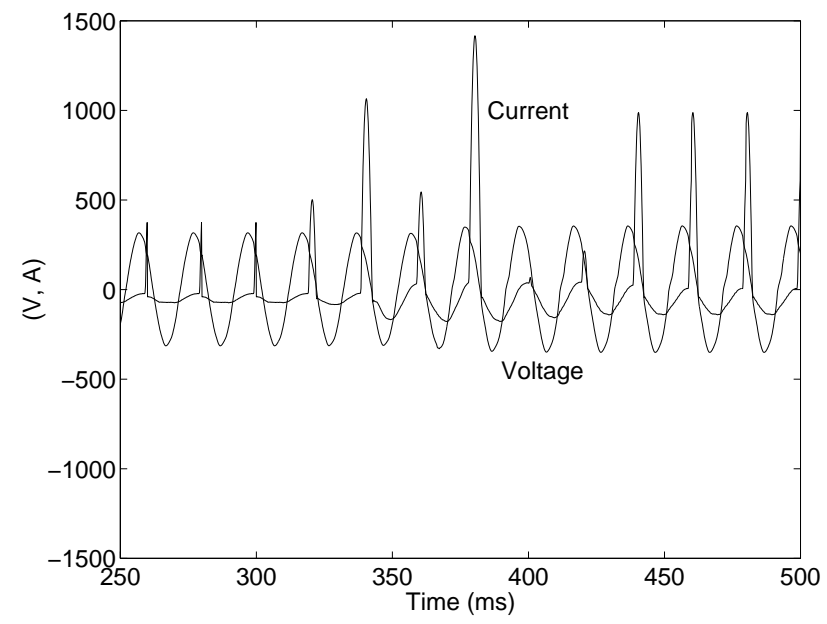

Figure 13. Effect of Voltage Sag on Heater Current

The peak heater current varies through the end of the sag, falling to almost zero at two instances before moving back to a constant value. The peak compensating current for this transient incident is 1217 Amps and the peak rate of change of current is $2.6 \mathrm{Amps} / \mu \mathrm{s}$.

\section{Design Requirements of The Shunt Active Filter}

The steady state and transient events place a number of operational requirements on a shunt active filter to be installed at the site. These are the steady state rating (average continuous current rating), peak rating (short term overload capability), peak compensating current and maximum rate of change of compensating current. Table I summarises this information for the transient events presented. Steady state and peak ratings are presented along with peak current and compensating current slew rates. The maximum compensating current requirement occurs for the induction motor start when the compensating current is the same as the load current for one cycle. The next largest peak current is $1301 \mathrm{~A}$ for the capacitor switching. The maximum rate of change of current is $6.3 \mathrm{Amps} / \mu \mathrm{s}$ for the capacitor switching event.

An active filter is usually realised with a controlled current

Table I. Active Filtering Rating and Design Information

\begin{tabular}{|l|l|l|l|l|l|l|}
\hline Event & $\begin{array}{l}\text { Steady State } \\
\text { Rating (kVA). } \\
\text { Before/After } \\
\text { Transient }\end{array}$ & $\begin{array}{l}\text { Peak } \\
\text { Rating, } \\
(\mathrm{kVA}) .\end{array}$ & $\begin{array}{l}\text { Peak } \\
\text { Compensating } \\
\text { Current (Amps) }\end{array}$ & $\begin{array}{l}\text { Peak Compensating } \\
\text { Current Slew Rate } \\
(\mathrm{Amps} / \mu \mathrm{s})\end{array}$ & $\begin{array}{l}\text { Max Filter } \\
\text { Inductance } \\
(\mu \mathrm{H})\end{array}$ & $\begin{array}{l}\text { Max Switching } \\
\text { Frequency }(20 \mathrm{~A} \\
\text { Hysteresis Band) } \\
(\mathrm{kHz})\end{array}$ \\
\hline \hline $\begin{array}{l}\text { Transient Load } \\
\text { Change }\end{array}$ & $4 / 4$ & 40 & 320 & 0.84 & 257 & 52 \\
\hline $\begin{array}{l}\text { Induction Motor } \\
\text { Start }\end{array}$ & $16 / 16$ & 376 & 2509 & 0.73 & 405 & 33 \\
\hline Capacitor Switching & $33 / 42$ & 110 & 1301 & 6.3 & 48 & 281 \\
\hline $\begin{array}{l}\text { Induction Motor } \\
\text { Heater Sag Response }\end{array}$ & $16 / 55$ & 98 & 1217 & 2.6 & 153 & 88 \\
\hline $\begin{array}{l}\text { Induction Motor } \\
\text { Heater Load (Steady } \\
\text { State) }\end{array}$ & $33 / 33$ & 33 & 450 & 0.79 & 343 & 39 \\
\hline
\end{tabular}


converter which uses a voltage source converter and output inductor [9]. This inductor determines the maximum rate of change of compensating current. If it is assumed that the active filter is a single phase device the peak of a $230 \mathrm{Vrms}$ $\mathrm{AC}$ voltage is $325 \mathrm{~V}$. Allowing a DC bus voltage of $525 \mathrm{VDC}$ gives a minimum inductor voltage of $200 \mathrm{~V}$. The maximum inductance that allows the filter to produce the required rate of change of current is determined by dividing the supply voltage by the required rate of change of current (Table I). The minimum inductance is determined from the point $\mathrm{n}$ the supply voltage waveform where the rate of change of current is maximum. The inductor size determines the switching frequency that is required to maintain current control. In hysteresis current control the inverter is switched to keep the current within the hysteresis band. The maximum switching frequency, which occurs when the supply voltage is zero [9], is shown in Table I for a $20 \mathrm{~A}$ hysteresis band.

These switching frequencies exceed those reasonably attainable with IGBTs. These switching frequencies are possible with MOSFET inverters suggesting that the high rate of change of current requirements of active filtering would be best met with a high speed MOSFET converter alongside a lower speed converter built with IGBTs. The higher switching frequency converter would provide the compensating current when the slower converter was unable to produce the required rate of change of current. Control systems for such arrangements of active filters have been proposed [10].

\section{CONCLUSION}

The performance of a shunt active filter at a real light industrial site has been evaluated by simulation using actual recorded measurements of power system transient and steady state incidents. The shunt active filter has been shown to be capable of lowering the distortion of the supply current and voltage in steady state and transient conditions. As such it is capable of power quality improvement. In order for the shunt active filter to produce improvement in the power quality during a transient the converter must have very large transient ratings, up to ten times the steady state rating, and be able to produce high rates of change of compensating current. This makes the active filter expensive to build as the transient rating requirements would be the dominant design constraint. It may also increase operating costs as the high rate of change of current requirement necessitates a high switching frequency.

When the rating of the active filter converter is limited during the transient, the power quality improvement from lowering the voltage distortion is lost. This is because the current limiting that occurs can introduce other distortion not present in the original transient. In one case the THD of the voltage waveform was higher when the filter had a limited current rating than it was if the active filter was not connected. This is important as it shows that the transient performance of shunt active filters must be further investigated and that active filters installed to correct steady state or slowly varying conditions could contribute little in the way of power quality improvement during a transient. They could even cause power quality degradation.

The very high rate of change of current that the active filter converter must produce means that the converter may have to use very fast switching devices such as MOSFETs rather than IGBTs. An arrangement where a smaller faster converter is used to provide the very fast rate of change of current along with a slower larger converter that produces the bulk of the current could be a cost effective solution to the high rate of change of current problem.

\section{ACKNOWLEDGMENTS}

The authors acknowledge the support of the New Zealand Foundation for Research, Science and Technology.

\section{REFERENCES}

[1] G. T. Heydt, Electric Power Quality, 2nd ed. Stars in a Circle Publications, West Lafayette, Indiana, USA:, 1991.

[2] J. Arrillaga, D. A. Bradley, and P. S. Bodger, Power System Harmonics. John Wiley and Sons, Chichester, UK, 1985.

[3] R. M. Duke and S. D. Round, "The Steady State Performance of a Controlled Current Active Filter," IEEE Transactions on Power Electronics, vol 8, no. 3, pp. 140-146, 1993.

[4] S. D. Round and D. M. E. Ingram, "An Evaluation of Techniques for Determining Active Filter Compensating Currents in Unbalanced Systems," presented at The European Power Electronics Conference, Trondheim, Norway pp. 4.767-4.772, 1997.

[5] H. D. Laird, S. D. Round, R. M. Duke, and A. Gardiner, "Power Quality Observations at a Light Industrial Site," to be presented at The International Conference on Harmonics in Power Systems, Athens, Greece, 1998.

[6] C. A. Quinn, N. Mohan, and H. A. Mehta, "A Four Wire, CurrentControlled Converter Provides Harmonic Neutralisation in Three Phase, Four Wire Systems," presented at Applied Power Electronics Conference, Boston, USA, pp. 829-836, 1993.

[7] H. Akagi, A. Nabae, and S. Atoh, "Control Strategy of Active Power Filters Using Multiple Voltage Source PWM Converters," IEEE Transactions on Industry Applications, vol. 22, no 3, pp. 460-465, 1986

[8] S. Bhattacharya, D. M. Divan, and B. Banerjee, "Synchronous Frame Harmonic Isolator," presented at The European Power Electronics Conference, Florence, Italy. pp. 3030-3035, 1991.

[9] D. M. Brod and D.W. Novotny, "Current Control of VSI-PWM Inverters," IEEE Transactions on Industry Appliactions, vol. 21, no 3, pp. 562-570, 1985.

[10] L. A. Moran, L. Fernandez, J. W. Dixon, and R. Wallace, “A Simple and Low-Cost Control Strategy for Active Power Filters Connected in Cascade," IEEE Transactions on Industrial Electronics, vol. 44, no 5, pp. 621-629, 1997.

\section{BIOGRAPHIES}

Simon Round holds a $\mathrm{BE}(\mathrm{Hons})$ and $\mathrm{PhD}$ from the University of Canterbury, Christchurch, New Zealand where he is currently a lecturer. His research interests include motor drives, active filtering and power electronics.

Hamish Laird Has a BE(Hons) and ME from the University of Canterbury,. He is currently pursuing a $\mathrm{PhD}$ at the same university.

Richard Duke holds a BSc, BE(Hons), ME and $\mathrm{PhD}$ all from the University of Canterbury where he is currently Head of the Electrical and Electronic Engineering Department.

Alister Gardiner is Electrotechnology Group Manager at Industrial Research Limited, Christchurch, New Zealand. 